\title{
Case Management for Frequent Users of Medical Care
}

\author{
Emily C. Giesler, DO, Grant Family Medicine \\ Michael E. Jobansen, MD, MS, Associate Editor \\ Ann Fam Med 2018;16(3):iii. https://doi.org/10.1370/afm.2256.
}

The Annals of Family Medicine encourages readers to develop a learning community to improve health care and health through enhanced primary care. Participate by conducting a RADICAL journal club. RADICAL stands for Read, Ask, Discuss, Inquire, Collaborate, Act, and Learn. We encourage diverse participants to think critically about important issues affecting primary care and act on those discussions. ${ }^{1}$

\section{HOW IT WORKS}

In each issue, the Annals selects an article and provides discussion tips and questions. Take a RADICAL approach to these materials and post a summary of your conversation in our online discussion. (Open the article and click on "TRACK Discussion/ Submit a comment.") Discussion questions and information are online at: http://www.annfammed.org/site/AJC/.

\section{CURRENT SELECTION}

\section{Article for Discussion}

Hudon C, Chouinard M-C, Dubois M-F, et al. Case management in primary care for frequent users of health care services: a mixed methods study. Ann Fam Med. 2018;16(3):232-239.

\section{Discussion Tips}

Mixed methods studies bring together the complementary strengths of quantitative and qualitative methods and can be quite useful in evaluating complex interventions. As systems of care become more complex, mixed methods will likely be seen more in the literature as they can lead to better understanding about interventions and outcomes. This study uses mixed methods to evaluate a randomized controlled trial of case management in primary care.

\section{Discussion Questions}

- What question is asked by this study and why does it matter?

- How does this study advance beyond previous research and clinical practice on this topic?
- How strong is the study design for answering the question?

- To what degree can the findings be accounted for by:

- How patients were selected, excluded, or lost to follow-up?

- The entrance criteria for patients into the randomized controlled trial?

- Who was selected for the qualitative portion of the study and the selection process?

- How the main variables were measured?

- Who was blinded in the study?

- Length of follow-up?

- Confounding (false attribution of causality because 2 variables discovered to be associated actually are associated with a 3 rd factor)?

- Chance?

- How the findings were interpreted?

- What are the main study findings? How do these findings compare with previous evaluations of case management?

- How do the qualitative findings influence your understanding of the quantitative findings, and vice versa?

- How comparable is the study sample to similar patients in your practice? Do you think the intervention could be implemented in your office?

-What contextual factors are important for interpreting the findings?

- How might this study change case management in your practice? Policy? Education? Research?

- What are the next steps in interpreting or applying the findings?

- What researchable questions remain?

\section{References}

1. Stange KC, Miller WL, McLellan LA, et al. Annals Journal Club: It's time to get RADICAL. Ann Fam Med. 2006;4(3):196-197. http:// annfammed.org/cgi/content/full/4/3/196. 